\title{
A Study of the Correlation between Angiotensin (1-7) and the Histopathological Changes in the Penises of Experimentally Diabetic Rats
}

\author{
Abdelaal M. El Kamshoushi', Nagat Sobhy', Suzan F. Helal'2, Passainte S. Hassaan ${ }^{3 *}$, Heba Omar ${ }^{1}$ \\ ${ }^{1}$ Dermatology, Venereology and Andrology Department, Faculty of Medicine, Alexandria University, Alexandria, Egypt \\ ${ }^{2}$ Pathology Department, Faculty of Medicine, Alexandria University, Alexandria, Egypt \\ ${ }^{3}$ Medical Physiology Department, Faculty of Medicine, Alexandria University, Alexandria, Egypt \\ Email: *Passainte.saber@alexmed.edu.eg, *Passaintehassaan@gmail.com
}

How to cite this paper: El Kamshoushi, A.M., Sobhy, N., Helal, S.F., Hassaan, P.S. and Omar, H. (2018) A Study of the Correlation between Angiotensin (1-7) and the Histopathological Changes in the Penises of Experimentally Diabetic Rats. Open Journal of Endocrine and Metabolic Diseases, 8, 81-92.

https://doi.org/10.4236/ojemd.2018.83009

Received: January 20, 2018

Accepted: March 19, 2018

Published: March 22, 2018

Copyright $(0) 2018$ by authors and Scientific Research Publishing Inc. This work is licensed under the Creative Commons Attribution International License (CC BY 4.0).

http://creativecommons.org/licenses/by/4.0/

\section{(c) (i) Open Access}

\begin{abstract}
Background: Diabetes mellitus is an important risk factor for erectile dysfunction. Renin-angiotensin system with its branches Angiotensin II and Angiotensin 1-7 [Ang-(1-7)] are altered in diabetes and could affect erection. So, in this study we determine the level of Ang-(1-7), nitrite (the major nitric oxide metabolite) and histopathological changes in penile tissues of type I diabetic rats. A total of 60 male albino rats were divided into two groups: group I (control) and group II (diabetic) for either 4 weeks in group IIa, or 8 weeks in group IIb. Diabetes was induced by intraperitoneal injection of streptozotocin (60 mg/kg). Penile levels of Ang-(1-7), nitrite and histopathological examination were assessed at 4 and 8 weeks after diabetes induction. Results: Ang-(1-7) and nitrite were decreased in diabetic rats at 4 weeks and continued to be lower at 8 weeks for Ang-(1-7) only. Loss of corpus cavernosum smooth muscle was present in $25 \%$ and $85 \%$ of rats at 4 and 8 weeks of diabetes respectively $(\mathrm{P}<0.001)$. The loss of smooth muscle was replaced by dense fibrous tissue and was correlated positively with the reduced Ang-(1-7). Conclusion: Diabetes induced progressive decrease in the release of Ang-(1-7) and nitric oxide from the corpora cavernosa in a time-dependent manner with concomitant fibro-muscular changes that end by corporal fibrosis affecting subsequently erectile functions.
\end{abstract}

\section{Keywords}

Angiotensin 1-7, Corpus Cavernosum, Erectile Dysfunction, Diabetes Mellitus, Rats 


\section{Introduction}

Erectile dysfunction (ED) is characterized by the inability to achieve and maintain adequate penile erection for satisfactory sexual intercourse [1]. Upon sexual stimulation, erection occurs by the release of neurotransmitters, mainly nitric oxide (NO) from the cavernous nerve terminals and subsequently the endothelium. It causes relaxation of smooth muscle cells in cavernosal arterioles and sinuses, resulting in an increased penile blood flow with partial occlusion of the venous outflow, causing erection [2].

Diabetes mellitus (DM) is an important risk factor for ED and one of the most difficult conditions to treat [3]. Nearly, 50\% of diabetic men will complain from ED within 10 years of the diagnosis [4]. It appears that disease progression limits the efficacy of conventional drugs like phosphodiesterase- 5 inhibitors. So, there is a need to discover newer more successful treatment based on a better understanding of the mechanisms of diabetic ED [5].

The pathogenesis of ED in diabetes is multifactorial. One of the most important pathophysiological mechanisms is endothelial dysfunction presented by the decreased NO bioavailability resulting in incomplete relaxation of the vascular smooth muscle of the corpora cavernosa (CC) [6]. Many factors are implicated in this dysfunction; namely increased levels of oxygen free radicals; impaired endothelial and neuronal NO synthesis and activity; and finally an imbalance between vasoconstrictive and vasorelaxant mediators favoring vasoconstriction [7] [8].

The renin-angiotensin system (RAS) has been shown to play an active role within the erectile tissues [9]. It includes two branches, one deleterious triggered by Angiotensin II (Ang II) and the other protective triggered by Angiotensin-(1-7) (Ang-(1-7)) [10]. It is evidenced now that Ang II is expressed in the penis in higher amount than that present in the systemic circulation [11]. It causes vasoconstriction, oxidative stress and fibrosis which are thought to play a critical role in the progression of diabetic ED [12] [13].

In the last decade, a counter-regulatory pathway in which Ang-(1-7) acts as the main effector has been discovered in the erectile tissue [14]. By acting through Mas receptor, which is highly expressed in the penile vasculature [15], Ang-(1-7) promotes many beneficial outcomes, including vasodilation [16] (Lemos et al., 2005), anti-inflammatory [17] and antiproliferative effects [18]. Recent evidence suggests the involvement of Ang-(1-7) in diabetic ED [12]. Acute, ex-vivo administration of Ang-(1-7) to diabetic rabbit corpus cavernosal segments was effective in attenuating diabetes or Ang II-induced hyper reactivity suggesting a possible role for Ang-(1-7) in the treatment of diabetic ED [19]. However, the exact mechanisms underlying this protection are still not fully understood.

Based on the concept that DM contributes to the onset of ED and that the RAS components are involved in both DM and ED, the purpose of this study was to assess the level of Ang-(1-7) and nitrite in the CC of diabetic rats at 4 and 
8 weeks after diabetes induction and to investigate the associated histopathological changes.

\section{Material and Methods}

The study was conducted on 60 adult male albino rats 8 - 10 weeks (150 - $200 \mathrm{~g})$ supplied by the laboratory of Physiology Department, Faculty of Medicine, Alexandria University. They were housed in plastic cages at room temperature with free access to standard diet and drinking water. All procedures were approved by the Ethics Committee of the Faculty of Medicine, Alexandria University.

Animals were randomly divided into two main groups: Group I: Nondiabetic control group $(n=20)$ and Group II: Diabetic group $(n=40)$ that was further subdivided into group IIa and IIb sacrificed at 4 and 8 weeks of DM respectively.

Diabetes was induced by a single intraperitoneal injection of freshly prepared streptozotocin in a dose of $60 \mathrm{mg} / \mathrm{Kg}$ (STZ; Sigma Chemical, St Louis, MO, USA) and dissolved in sterile citrate buffer ( $\mathrm{pH} 4.5)$ [20]. Nondiabetic rats were injected with an equivalent volume of saline. 72 hours after STZ injection, the rats were examined for blood glucose via tail vein prick using glucose-oxidase reagent strips (One Touch Ultra, Johnson \& Johnson', New Brunswick, NJ, USA). Rats with fasting blood glucose (FBG) levels $>300 \mathrm{mg} / \mathrm{dL}$ were classified as diabetic and included in the study [21]. Rats that did not develop diabetes or dead during the experiment were replaced by others. No hypoglycemic drugs were given in the study.

\subsection{Tissue Preparation}

At the end of the study, at 4 weeks of saline or STZ injection in group I or group IIa or at 8 weeks of STZ injection in group IIb, FBG was checked after an overnight fasting. Then, rats were anesthetized intramuscularly with a mixture of ketamine $(10 \mathrm{mg} / \mathrm{kg})$ and xylazine $(2 \mathrm{mg} / \mathrm{kg})$ and sacrificed.

The penis was removed en bloc by doing a circular incision at its base with removal of the foreskin, shaft skin and amputation of the penis at the most proximal position in relation to the body. It was gently blotted on sterile cotton gauze to remove excess blood and the underlying cavernosal tissue was dissected from the adjacent connective tissue and cut into two longitudinal halves.

One halves of the penises were stored at $-80^{\circ} \mathrm{C}$ until homogenization of 100 $\mathrm{mg}$ of each tissue sample in cold phosphate buffered saline $(0.01 \mathrm{~mol} / \mathrm{L}, \mathrm{pH} 7.0$ 7.2). The homogenate was centrifuged at $5000 \times \mathrm{g}$ for 15 minutes at $4^{\circ} \mathrm{C}$ and the supernatant was stored at $-80^{\circ} \mathrm{C}$ until use [20].

\subsection{Biochemical Assessment of Ang-(1-7) by ELISA}

Ang-(1-7) levels were determined in the supernatant' aliquots with an ELISA kit using Rat Ang-(1-7) specific monoclonal antibodies according to the manufacturer's instructions (Cloud-Clone Corp, Houtston, TX, USA). For results nor- 
malization, the amount of total protein in each sample was estimated using Lowry's method [22], and Tissue Ang-(1-7) was expressed as pg/mg protein.

\subsection{Measurement of Nitrites}

Nitrite, the primary metabolite of nitric oxide, was quantified colorimetrically in the penile tissue homogenate using Griess Reagents and its results were expressed as $\mu \mathrm{mol} / \mathrm{mg}$ protein [23].

\subsection{Histopathological Examination of Penile Tissues}

The other halves of excised penises were immersed immediately in 10\% buffered formalin for 24 hours. Specimens were embedded subsequently in paraffin and sectioned at $5 \mu \mathrm{m}$ using a rotor microtome. Sections were stained using Hematoxylin-Eosin (H \& E) and Masson's trichrome (MT) stains to assess the extent of corporal fibrosis if present [24]. All histopathological analyses were performed in $200 \times$ magnification images.

\subsection{Statistical Analysis}

All data were expressed as mean $\pm \mathrm{SD}$. To compare among multiple groups, one-way analysis of variance (ANOVA) was used. Post Hoc least significant difference test (LSD) was employed for comparison between each 2 groups. All statistical analyses were performed using SPSS version 20.0 for Windows (SPSS Inc., Chicago, Illinois). Statistical significance was set at $\mathrm{P} \leq 0.05$.

\section{Results}

\subsection{Biochemical Analysis}

\subsubsection{Blood Glucose Levels}

STZ-induced diabetes led to a significant elevation in blood glucose level.72 hours after diabetes induction, the mean FBG was $405.8 \pm 57 \mathrm{mg} / \mathrm{dl}$ in diabetic rats by contrast to normal ones which had FBG $71.5 \pm 7.09 \mathrm{mg} / \mathrm{dl}$. Hyperglycemia persisted in diabetic rats and was $430.65 \pm 50.77 \mathrm{mg} / \mathrm{dl}$ after 4 weeks of diabetes in group IIa and $510.9 \pm 40.64 \mathrm{mg} / \mathrm{dl}$ after 8 weeks in group IIb. Significant increase in FBG was noted in group IIb in relation to group IIa $(\mathrm{P}<0.001)$.

\subsubsection{Penile Levels of Ang-(1-7)}

The mean level of Ang-(1-7) in penile tissue of normal rats was $55.26 \pm 19.42$ $\mathrm{pg} / \mathrm{mg}$ protein. It decreased significantly in diabetic rats as compared to normal ones to reach $24.70 \pm 8.07$ and $11.66 \pm 5.13 \mathrm{pg} / \mathrm{mg}$ protein at 4 and 8 weeks of diabetes in group IIa and IIb respectively $(\mathrm{P}<0.001)$. Importantly, the duration of diabetes was shown to affect the release of Ang-(1-7) where its mean level decreased significantly at 8 weeks of diabetes in group IIb as compared to 4 weeks in group IIa $(\mathrm{P}=0.002)$ (Figure $1(\mathrm{a})$ ).

\subsubsection{Penile Levels of Nitrite}

The mean nitrite level in the $\mathrm{CC}$ of control rats was $13.80 \pm 3.47 \mu \mathrm{mol} / \mathrm{mg}$ 


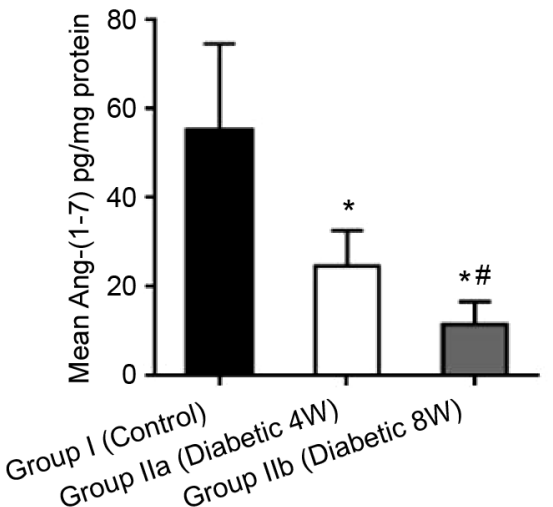

(a)

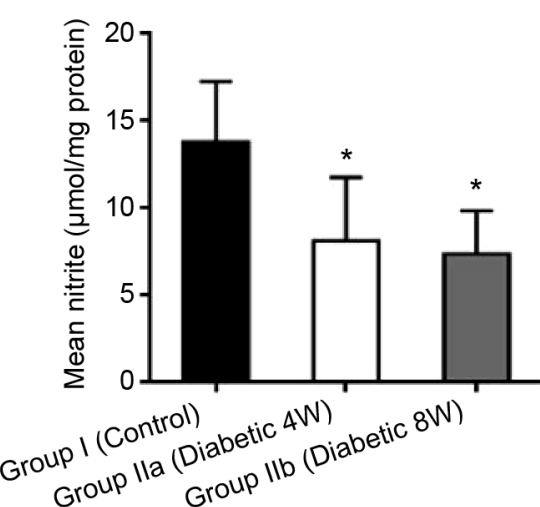

(b)

Figure 1. The levels of Ang-(1-7) in $\mathrm{pg} / \mathrm{mg}$ protein and nitrite in $\mu \mathrm{mol} / \mathrm{mg}$ protein in corpus cavernosum of normal and diabetic rats at 4 and 8 weeks after STZ injection. One way ANOVA test was used to analyze the data presented as mean $\pm \mathrm{SD}$, where $\mathrm{P}<0.001$.

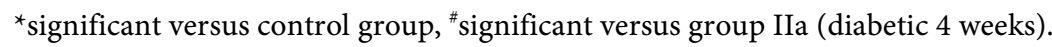

protein. It decreased significantly and became $8.12 \pm 3.67$ and $7.37 \pm 2.49$ $\mu \mathrm{mol} / \mathrm{mg}$ protein after 4 and 8 weeks of diabetes in group IIa and IIb respectively as compared to normal control rats in group I $(\mathrm{P}<0.001)$. No significant difference was observed in the nitrite level between both diabetic groups where $\mathrm{P}=$ 0.738 (Figure 1(b)).

\subsection{Histopathological Changes of Corpora Cavernosa of Rats' Penises (Table 1, Figure 2)}

Examination of $\mathrm{H} \& \mathrm{E}$ sections of normal penile tissues revealed normal smooth muscle bundles surrounding the blood vessels of CC. In diabetic rats, there was a decrease in these bundles.

These results were confirmed by Masson's Trichrome staining. The smooth muscles were identified as normal with no change, with mild, moderate decrease or total loss of muscle mass. Significant loss was noted in diabetic rats in relation to normal ones $(\mathrm{P}<0.001)$. This loss was significantly higher in group IIb (total loss of smooth muscle mass in $85 \%$ of rats) relative to group IIa (total loss in $25 \%$ of rats $)(\mathrm{P}<0.001)$ reflecting worsening of the condition with progression of DM.

Concerning the fibrotic changes, the penile specimens were categorized as normal with no fibrosis, with mild, moderate or severe fibrosis. Normal appearance of corporal smooth muscle was noted in normal healthy rats. In contrast, fibrous tissue deposition appeared at 4 weeks of diabetes in group IIa and reached dense fibrosis in $25 \%$ of rats. It continued progressively at 8 weeks in group IIb resulting in dense fibrosis in $80 \%$ of rats. A significant increase in corporal fibrosis was noted in group IIb in relation to group IIa $(\mathrm{P}<0.001)$.

\subsection{Relation between Ang-(1-7), NO and Histopathological Changes in Diabetic Rat Penises}

In this study, there was no association between the levels of Ang-(1-7) and NO 
Table 1. Comparison between the studied groups according to the histopathological changes in the CC.

\begin{tabular}{|c|c|c|c|c|c|c|c|}
\hline & \multicolumn{2}{|c|}{ Group I (Control) } & \multicolumn{2}{|c|}{ Group IIa (Diabetic $4 \mathrm{~W}$ ) } & \multicolumn{2}{|c|}{ Group IIb (Diabetic 8W) } & \multirow{2}{*}{$P$ value } \\
\hline & No. & $\%$ & No. & $\%$ & No. & $\%$ & \\
\hline \multicolumn{8}{|l|}{ Smooth muscle mass } \\
\hline Normal & 20 & 100.0 & 0 & 0.0 & 0 & 0.0 & \multirow{4}{*}{$<0.001^{*}$} \\
\hline Mild decrease & 0 & 0 & 7 & 35.0 & 0 & 0.0 & \\
\hline Moderate decrease & 0 & 0 & 8 & 40.0 & 3 & 15.0 & \\
\hline Total loss & 0 & 0 & 5 & 25.0 & 17 & 85.0 & \\
\hline \multicolumn{8}{|l|}{ Corporal fibrosis } \\
\hline No fibrosis & 20 & 100.0 & 0 & 0.0 & 0 & 0.0 & \multirow{4}{*}{$<0.001^{*}$} \\
\hline Mild & 0 & 0.0 & 9 & 45.0 & 0 & 0.0 & \\
\hline Moderate & 0 & 0.0 & 6 & 30.0 & 4 & 20.0 & \\
\hline Dense & 0 & 0.0 & 5 & 25.0 & 16 & 80.0 & \\
\hline Significance between groups & \multicolumn{7}{|c|}{$\begin{array}{l}\mathrm{P}_{1}<0.001^{*}, \mathrm{P}_{2}<0.001^{*}, \mathrm{P}_{3}<0.001^{*} \text { (muscle mass) } \\
\mathrm{P}_{1}<0.001^{*}, \mathrm{P}_{2}<0.001^{*}, \mathrm{P}_{3}=0.001^{*} \text { (fibrosis) }\end{array}$} \\
\hline
\end{tabular}

$\chi^{2}:$ Chi square test, $\mathrm{MCp}=\mathrm{P}$ value for Monte Carlo test, P1: P value between control and diabetic 4 weeks; P2: P value between control and diabetic 8 weeks; $\mathrm{P}$ : $\mathrm{P}$ value between diabetic groups at 4 and 8 weeks. ${ }^{*}$ : Statistically significant at $\mathrm{P} \leq 0.05$.
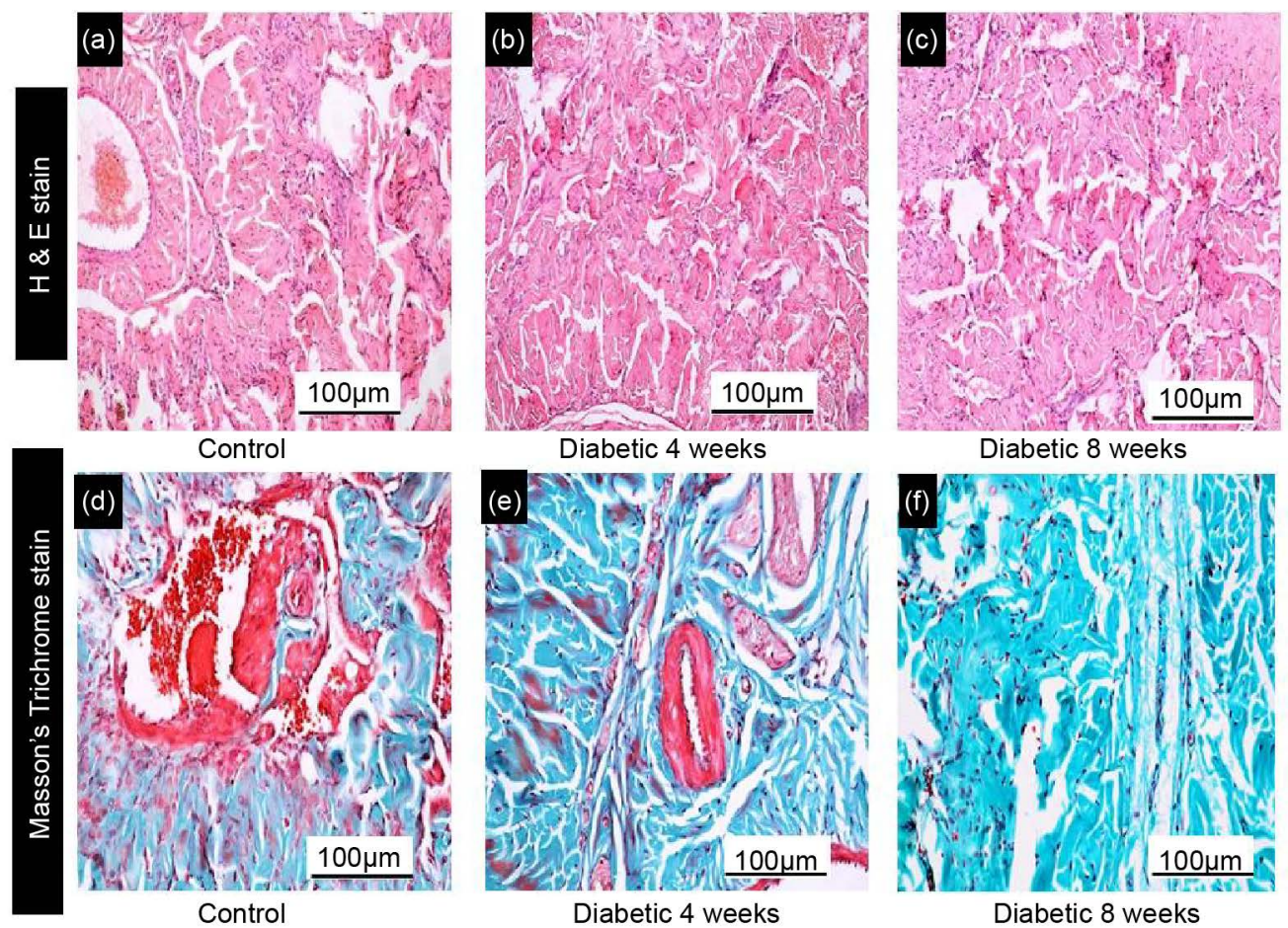

Figure 2. Histopathological features of the CC tissue sections in the two groups (H \& E stain and Masson's trichrome stain). Top: H \& E staining: (a) Representative figure of normal smooth muscle bundles surrounding blood vessels in CC of a normal rat. (b) Partial loss of corporal smooth muscles in a diabetic rat of group IIa. This progresses in (c) to near disappearance of smooth muscle in a rat of group IIb. Bottom: Masson's trichrome staining: (d) Normal smooth muscle bundles (red) with minimal connective tissue (blue) in a normal rat. (e) Decrease in smooth muscle with increase in fibrous tissue bands in a rat of group IIa. (f) More intensification of fibrotic changes with severe loss of smooth muscle in a rat of group IIb. (Original magnification $\times 200$. Scale bars $100 \mu \mathrm{m})$. 
in rats at 4 and 8 weeks of diabetes $(\mathrm{r}=-0.072, \mathrm{P}=0.761$ and $\mathrm{r}=0.183, \mathrm{P}=$ 0.439 respectively).

By contrast, a negative correlation was demonstrated between the level of Ang-(1-7), the degree of smooth muscle loss and corporal fibrosis in group IIa $(\mathrm{P}<0.001, \mathrm{P}=0.02$ respectively) and group $\mathrm{IIb}(\mathrm{P}=0.004, \mathrm{P}=0.001$ respectively) (Table 2).

\subsection{Relation between FBG, Ang-(1-7) and Histopathological Changes in Diabetic Rat Penises}

There was no significant relation between FBG and the tissue level of Ang-(1-7) along the entire study period ( $\mathrm{P}=0.123$ in group IIa and $\mathrm{P}=0.368$ in group IIb). The same was noted between FBG and histopathological changes of CC concerning the loss of smooth muscle and corporal fibrosis in the studied groups $(\mathrm{P}$ $=0.908, \mathrm{P}=0.339$ in group IIa respectively) and $(\mathrm{P}=0.229, \mathrm{P}=0.089$ in group IIb respectively). The impact of diabetes was related mainly to the duration of diabetes not the level of FBG.

\section{Discussion}

Ang-(1-7) and the sequential histopathological changes occurring in the erectile tissue of type I diabetic rats were the scope of the present study. Intraperitoneal injection of STZ induced severe hyperglycemia after 72 hours. The changes in FBG level increased significantly along the period of the study. This could be attributed to the progressive damage of $\mathcal{B}$-cells of islets of Langerhans due to apoptosis and necrosis caused by DNA damage, depletion of cellular energy and production of oxygen free radicals [25].

This hyperglycemia affected harmfully the release of penile Ang-(1-7) which decreased significantly after 4 weeks of diabetes induction and kept on decreasing after 8 weeks also. This finding raises evidence on a possible role of Ang-(1-7) in the pathogenesis of diabetic ED. Yousif et al. (2007) [19] showed impaired Ang-(1-7) mediated relaxation of diabetic CC suggesting that ED caused by

Table 2. Relation between tissue Ang-(1-7) in pg/mg and histopathological changes in diabetic rats.

\begin{tabular}{ccc}
\hline & \multicolumn{2}{c}{ Ang-(1-7) } \\
\hline & $\boldsymbol{r}$ & $\boldsymbol{P}$ \\
\hline Smooth muscle mass loss & & \\
Group IIa (Diabetic 4W) & -0.731 & $<0.001^{*}$ \\
Group IIb (Diabetic 8W) & -0.619 & $0.004^{*}$ \\
Corporal fibrosis & & \\
Group IIa (Diabetic 4W) & -0.516 & $0.020^{*}$ \\
Group IIb (Diabetic 8W) & -0.672 & $0.001^{*}$ \\
\hline
\end{tabular}

A negative correlation was noted between Ang-(1-7) and each of smooth muscle mass loss and corporal fibrosis. $r$. Pearson coefficient, ${ }^{\star}$ Statistically significant at $\mathrm{P} \leq 0.05$. 
diabetes may be partly due to decreased Ang-(1-7) production in CC.

It becomes evident that the pro-erectile functions of Ang-(1-7) are mediated by several mechanisms; namely enhancement of NO-mediated vasodilatation, and inhibition of penile fibrosis [12] [15].

In this study, the release of NO from the CC was affected by the state of diabetes. The level of nitrite; the primary metabolite of NO, was decreased in diabetic rats as compared to normal ones. This decrease continued but was not significant with the progression of diabetes.

Several in vivo and ex vivo studies showed that the relaxation effects of Ang-(1-7) in CC of diabetic rats are mediated mainly via NO/cGMP by increasing NO production/bioavailability [19]. Additionally, chronic treatment with Ang-(1-7) increased both endothelial and neuronal nitric oxide synthase (NOS) protein expression in a mouse model of hypercholesterolaemia-induced ED [26]. Also, chronic treatment with Ang-(1-7) was found to reverse up regulation of Rho kinases in the diabetic CC [27]. Inhibition of these enzymes was found to increase NO signaling, and attenuate corporal fibrosis improving subsequently erectile function [28] [29]. These findings together support the crucial role of increased NO in mediating the pro-erectile functions of Ang-(1-7).

However, an unaltered NO levels with a marked decrease in cGMP levels in CC with diabetes progression suggested that Ang-(1-7) might not act only through stimulation of NO production but also through the regulation of phosphodiesterase enzyme responsible for cGMP degradation. PDE activity is markedly increased in CC of diabetic rats and Ang-(1-7)-mediated relaxation might occur by increasing cGMP levels through transcriptional regulation of PDE gene [30]. These findings may explain the absence of association between Ang-(1-7) and $\mathrm{NO}$ in addition to the difference in the time-dependent decrease of both Ang-(1-7) and NO levels with the progression of diabetes.

From another side, the structural changes that could affect the erectile tissue with diabetes especially the fibrotic changes would make the CC not only less functional during erection but also less responsive to local (prostaglandin E1) and systemic (phosphodiesterase-5 inhibitors) vasodilators [31]. Therefore, it was important in our study to assess the histopathological changes of diabetic penile tissues. The pathologic examination revealed progressive loss of smooth muscle mass with concomitant corporal fibrosis. These changes were more pronounced at 8 weeks than at 4 weeks of diabetes. As smooth muscle relaxation of the intracavernosal sinuses caused by NO release play a key role in achieving and maintaining erection, reduction of smooth muscle cells will result in decreased intracavernosal pressure and subsequently ED [32].

These results coincide with an alloxan-induced rabbit model of diabetes, in which severely diabetic rabbits with blood glucose greater than $400 \mathrm{mg} / \mathrm{dl}$ had a pronounced decrease in trabecular smooth muscle versus controls. The reduction in smooth muscle was correlated with the decrease in corporeal vascular volume, and cavernous artery diameter in diabetic rabbit penises. This potential 
arterial insufficiency as well as the increase in diffuse connective tissue of CC may contribute to the pathophysiology of diabetic ED [33]. Interestingly, another report showed that the mRNA expression of smooth muscle $\alpha$-actin, and smooth muscle myosin heavy chain were decreased in diabetic rats with ED [34].

Importantly, in the current study, the progressive deterioration of smooth muscle mass and corporal fibrosis were significantly related to the decreased level of Ang-(1-7) along the whole period of the study. An inhibitory effect of Ang-(1-7) was noted via its receptor on the key signaling pathways of fibrogenesis [35]. This was evident in mice lacking Mas receptor, which suffered from penile fibrosis with severely depressed responses to electrical stimulation of the major pelvic ganglion [36]. Interestingly, Ang-(1-7) has been shown to reduce penile fibrosis and improve penile function when administrated orally in mice with hypercholesterolemia [26]. Kilarkaje et al. (2013) [37] reported also the ability of Ang-(1-7) to restore DM-induced structural changes in CC by reducing the degeneration of the corporeal smooth muscles seen in diabetic rats.

In the present study, it was evident also that the changes in FBG level had no significant relation to the level of penile Ang-(1-7), the deterioration of smooth muscle or the degree of corporal fibrosis. Importantly, Yousif et al. (2007) [19] detected that chronic treatment with Ang-(1-7) was able to reverse diabetes-induced abnormal CC vascular reactivity without correcting hyperglycemia.

Lastly, in addition to blocking the development of penile fibrosis, Ang-(1-7) was shown to enhance revascularization of the affected penis. Treatment with Ang-(1-7) for 4 weeks was demonstrated to reverse diabetes-induced decrease in VEGF-mediated angiogenesis in the cavernosa of diabetic mice [38]. This may represent a new hope to prevent or even minimize the corporal fibrosis which could lead to irreversible damage of erectile tissue.

\section{Conclusion}

In conclusion, in this study, we showed that diabetes induced progressive decrease in the release of penile Ang-(1-7), nitric oxide with concomitant loss of normal smooth muscle of the CC and its replacement by fibrotic tissue. The association of Ang-(1-7) with these histopathological changes provides support for future studies to elucidate the mechanisms by which Ang-(1-7) can act to modulate fibrosis and vascular remodeling in erectile dysfunction. A greater understanding of these processes in addition to its impact on inflammation and vascular proliferation will make Ang-(1-7) an attractive target for the development of new therapeutics for erectile dysfunction.

\section{References}

[1] Singh, J.C., Devasia, A., Gnanaraj, L. and Chacko, K.N. (2005) Erectile Dysfunction. National Medical Journal of India, 18, 139-143.

[2] Dean, R.C. and Lue, T.F. (2005) Physiology of Penile Erection and Pathophysiology of Erectile Dysfunction. Urologic Clinics of North America, 32, 379-395. https://doi.org/10.1016/j.ucl.2005.08.007 
[3] Chitaley, K., Kupelian, V., Subak, L. and Wessells, H. (2009) Diabetes, Obesity and Erectile Dysfunction: Field Overview and Research Priorities. Journal of Urology, 182, S45-S50. https://doi.org/10.1016/j.juro.2009.07.089

[4] Vinik, A.I. and Erbas, T. (2001) Recognizing and Treating Diabetic Autonomic Neuropathy. Cleveland Clinical Journal of Medicine, 68, 928-944.

https://doi.org/10.3949/ccjm.68.11.928

[5] Cellek, S., Cameron, N.E., Cotter, M.A. and Muneer, A. (2013) Pathophysiology of Diabetic Erectile Dysfunction. Potential Contribution of Vasa Nervorum and Advanced Glycation End Products. International Journal of Impotence Research, 25, 1-6. https://doi.org/10.1038/ijir.2012.30

[6] Maiorino, M.I., Bellastella, G. and Esposito, K. (2014) Diabetes and Sexual Dysfunction: Current Perspectives. Diabetes, Metabolic Syndrome and Obesity, 7, 95-105.

[7] Thorve, V.S., Kshirsagar, A.D., Vyawahare, N.S., Joshi, V.S., Ingale, K.G. and Mohite, R.J. (2011) Diabetes-Induced Erectile Dysfunction: Epidemiology, Pathophysiology and Management. Journal of Diabetes and its Complications, 25, 129-136. https://doi.org/10.1016/j.jdiacomp.2010.03.003

[8] Malavige, L.S. and Levy, J.C. (2009) Erectile Dysfunction in Diabetes Mellitus. Journal of Sexual Medicine, 6, 1232-1247. https://doi.org/10.1111/j.1743-6109.2008.01168.x

[9] Ma, T.K., Kam, K.K., Yan, B.P. and Lam, Y.Y. (2010) Renin-Angiotensin-Aldosterone System Blockade for Cardiovascular Diseases: Current Status. British Journal of Pharmacology, 160, 1273-1292. https://doi.org/10.1111/j.1476-5381.2010.00750.x

[10] Ferreira, A.J. and Santos, R.A. (2005) Cardiovascular Actions of Angiotensin-(1-7). Brazilian Journal of Medical and Biological Research, 38, 499-507. https://doi.org/10.1590/S0100-879X2005000400003

[11] Becker, A.J., Uckert, S., Stief, C.G., Scheller, F., Knapp, W.H., Hartmann, U. and Jonas, U. (2001) Plasma Levels of Angiotensin II during Different Penile Conditions in the Cavernous and Systemic Blood of Healthy Men and Patients with Erectile Dysfunction. Urology, 58, 805-810. https://doi.org/10.1016/S0090-4295(01)01312-7

[12] Fraga-Silva, R.A., Montecucco, F., Mach, F., Santos, R.A. and Stergiopulos, N. (2013) Pathophysiological Role of the Renin-Angiotensin System on Erectile Dysfunction. European Journal of Clinical Investigation, 43, 978-985. https://doi.org/10.1111/eci.12117

[13] Jin, L.M. (2009) Angiotensin II Signaling and Its Implication in Erectile Dysfunction. Journal of Sexual Medicine, 6, 302-310. https://doi.org/10.1111/j.1743-6109.2008.01188.x

[14] Santos, R.A., Ferreira, A.J., Verano-Braga, T. and Bader, M. (2013) Angiotensin-Converting Enzyme 2, Angiotensin-(1-7) and Mas: New Players of the Renin-Angiotensin System. Journal of Endocrinology, 216, R1-R17.

[15] da Costa-Goncalves, A.C., Fraga-Silva, R.A., Leite, R. and Santos, R.A. (2013) AVE 0991, a Nonpeptide Mas-Receptor Agonist, Facilitates Penile Erection. Experimental Physiology, 98, 850-855.

[16] Lemos, V.S., Silva, D.M., Walther, T., Alenina, N., Bader, M. and Santos, R.A. (2005) The Endothelium-Dependent Vasodilator Effect of the nonpeptideAng (1-7) Mimic AVE 0991 Is Abolished in the Aorta of Mas-Knockout Mice. Journal of Cardiovascular Pharmacology, 46, 274-279. https://doi.org/10.1097/01.fjc.0000175237.41573.63

[17] da Silveira, K.D., Coelho, F.M., Vieira, A.T., Sachs, D., Barroso, L.C., Costa, V.V., Bretas, T.L., Bader, M., de Sousa, L.P., da Silva, T.A., dos Santos, R.A., Simões e Sil- 
va, A.C. and Teixeira, M.M. (2010) Anti-Inflammatory Effects of the Activation of the Angiotensin-(1-7) Receptor, MAS, in Experimental Models of Arthritis. Journal of Immunology, 185, 5569-5576.

[18] Iwata, M., Cowling, R.T., Gurantz, D., Moore, C., Zhang, S., Yuan, J.X. and Greenberg, B.H. (2005) Angiotensin-(1-7) Binds, to Specific Receptors on Cardiac Fibroblasts to Initiate Antifibrotic and Antitrophic Effects. American Journal of Physiology, Heart and Circulatory Physiology, 289, H2356-2363. https://doi.org/10.1152/ajpheart.00317.2005

[19] Yousif, M.H., Kehinde, E.O. and Benter, I.F. (2007) Different Responses to Angiotensin-(1-7) in Young, Aged and Diabetic Rabbit Corpus Cavernosum. Pharmacological Research, 56, 209-216. https://doi.org/10.1016/j.phrs.2007.05.008

[20] Lin, F. and Gou, X. (2013) Panax Notoginseng Saponins Improve the Erectile Dysfunction in Diabetic Rats by Protecting the Endothelial Function of the Penile Corpus Cavernosum. International Journal of Impotence Research, 25, 206-211. https://doi.org/10.1038/ijir.2013.19

[21] Zhou, F., Xin, H., Liu, T., Li, G.Y., Gao, Z.Z., Liu, J., Li, W.R., Cui, W.S., Bai, G.Y., Park, N.C. and Xin, Z.C. (2012) Effects of Icariside II on Improving Erectile Function in Rats with Streptozotocin-Induced Diabetes. Journal of Andrology, 33, 832-844. https://doi.org/10.2164/jandrol.111.015172

[22] Lowry, O.H., Rosebrough, N.J., Farr, A.L. and Randall, R.J. (1951) Protein Measurement with the Folin Phenol Reagent. Journal of Biological Chemistry, 193, 265-275.

[23] Ozmen, H., Polat, F. and Cukurovalim, A. (2006) Spectrophotometric Determination of Nitrite in Water Samples with 4-(1-Methyl-1-Mesitylcyclobutane-3-yl)-2-Aminothiazole. Analytical Letters, 39, 823-833. https://doi.org/10.1080/00032710600611590

[24] Toblli, J.D., Stella, I., Inserra, F., Ferder, L., Zeller, F. and Mazza, O.N. (2000) Morphological Changes in Cavernous Tissue in Spontaneously Hypertensive Rats. American Journal of Hypertension, 13, 686-692. https://doi.org/10.1016/S0895-7061(99)00268-X

[25] Szkudelski, T. (2010) The Mechanism of Alloxan and Streptozotocin Action in B Cells of the Rat Pancreas. Physiological Research, 50, 537-546.

[26] Fraga-Silva, R.A., Costa-Fraga, F.P., Savergnini, S.Q., De Sousa, F.B., Montecucco, F., da Silva, D., Sinisterra, R.D., Mach, F., Stergiopulos, N., da Silva, R.F. and Santos R.A. (2013) An Oral Formulation of Angiotensin-(1-7) Reverses Corpus Cavernosum Damages Induced by Hypercholesterolemia. Journal of Sexual Medicine, 10, 2430-2442. https://doi.org/10.1111/jsm.12262

[27] Yousif, M.H., Makki, B., El-Hashim, A.Z., Akhtar, S. and Benter, I.F. (2014) Chronic Treatment with Ang-(1-7) Reverses Abnormal Reactivity in the Corpus Cavernosum and Normalizes Diabetes-Induced Changes in the Protein Levels of ACE, ACE2, ROCK1, ROCK2 and Omega-Hydroxylase in a Rat Model of Type 1 Diabetes. Journal of Diabetes Research, 2014, Article ID: 142154.

https://www.ncbi.nlm.nih.gov/pubmed/25309930

[28] Hannan, J.L., Albersen, M., Kutlu, O., Gratzke, C., Stief, C.G., Burnett, A.L., Lysiak, J.J., Hedlund, P. and Bivalacqua, T.J. (2013) Inhibition of Rho Kinase Improves Erectile Function, Increases Nitric Oxide Signaling and Decreases Penile Apoptosis in a Rat Model of Cavernous Nerve Injury. Journal of Urology, 189, 1155-1161. https://doi.org/10.1016/j.juro.2012.09.104

[29] Cho, M.C., Park, K., Chai, J.S., Lee, S.H., Kim, S.W. and Paick, J.S. (2011) Involvement of Sphingosine-1-Phosphate/RhoA/Rho-Kinase Signaling Pathway in Corporal Fibrosis Following Cavernous Nerve Injury in Male Rats. Journal of Sexual Medi- 
cine, 8, 712-721. https://doi.org/10.1111/j.1743-6109.2010.02147.x

[30] Dhaunsi, G.S., Yousif, M., Makki, B., Akhtar, S. and Benter, I.F. (2017) Angiotensin-(1-7) Downregulates Diabetes-Induced cGMP Phosphodiesterase Activation in Rat Corpus Cavernosum. BioMed Research International, 2017, Article ID: 5084961. https://www.ncbi.nlm.nih.gov/pubmed/28299329 https://doi.org/10.1155/2017/5084961

[31] Iacono, F., Giannella, R., Somma, P., Manno, G., Fusco, F. and Mirone, V. (2005) Histological Alterations in Cavernous Tissue after Radical Prostatectomy. Journal of Urology, 173, 1673-1676. https://doi.org/10.1097/01.ju.0000154356.76027.4f

[32] Palese, M.A., Crone, J.K. and Burnett, A.L. (2003) A Castrated Mouse Model of Erectile Dysfunction. Journal of Andrology, 24, 699-703. https://doi.org/10.1002/j.1939-4640.2003.tb02729.x

[33] Simopoulos, D.N., Gibbons, S.J., Malysz, J., Szurszewski, J.H., Farrugia, G., Ritman, E.L., Moreland, R.B. and Nehra, A. (2001) Corporeal Structural and Vascular Micro Architecture with X-Ray Micro Computerized Tomography in Normal and Diabetic Rabbits: Histopathological Correlation. Journal of Urology, 165, 1776-1782. https://doi.org/10.1016/S0022-5347(05)66413-0

[34] Wei, A.Y., He, S.H., Zhao, J.F., Liu, Y., Liu, Y., Hu, Y.W., Zhang, T. and Wu, Z.Y. (2012) Characterization of Corpus Cavernosum Smooth Muscle Cell Phenotype in Diabetic Rats with Erectile Dysfunction. International Journal of Impotence, 24, 196-201. https://doi.org/10.1038/ijir.2012.16

[35] Simões e Silva, A.C., Silveira, K.D., Ferreira, A.J. and Teixeira, M.M. (2013) ACE2, Angiotensin-(1-7) and Mas Receptor Axis in Inflammation and Fibrosis. British Journal of Pharmacology, 169, 477-492. https://doi.org/10.1111/bph.12159

[36] da Costa Gonçalves, A.C., Leite, R., Fraga-Silva, R.A., Pinheiro, S.V., Reis, A.B., Reis, F.M., Touyz, R.M., Webb, R.C., Alenina, N., Bader, M. and Santos, R.A. (2007) Evidence That the Vasodilator Angiotensin-(1-7)-Mas Axis Plays an Important Role in Erectile Function. American Journal of Physiology. Heart and Circulatory Physiology, 293, H2588-2596. https://doi.org/10.1152/ajpheart.00173.2007

[37] Kilarkaje, N., Yousif, M.H.M., El-Hashim, A.Z., Makki, B., Akhtar, S. and Benter, I.F. (2013) Role of Angiotensin II and Angiotensin-(1-7) in Diabetes-Induced Oxidative DNA Damage in the Corpus Cavernosum. Fertility and Sterility, 100, 226-233. https://doi.org/10.1016/j.fertnstert.2013.02.046

[38] Singh, N., Vasam, G., Pawar, R. and Jarajapu, Y.P. (2014) Angiotensin-(1-7) Reverses Angiogenic Dysfunction in Corpus Cavernosum by Acting on the Microvasculature and Bone Marrow-Derived Cells in Diabetes. Journal of Sexual Medicine, 11, 2153-2163. https://doi.org/10.1111/jsm.12620 